\title{
CORRECTION
}

\section{Correction to: Spontaneous neck hematoma secondary to parathyroid adenoma: a case series}

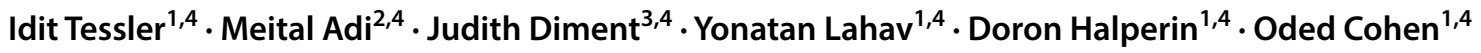

Published online: 29 April 2020

○) Springer-Verlag GmbH Germany, part of Springer Nature 2020

\section{Correction to: European Archives of Oto-Rhino-Laryngology \\ https://doi.org/10.1007/s00405-020-05959-z}

In the original publication of the article, one of the author name was published incorrectly as "Judith Diamant". The correct name is "Judith Diment".

The original article was updated.

Publisher's Note Springer Nature remains neutral with regard to jurisdictional claims in published maps and institutional affiliations.

The original article can be found online at https://doi.org/10.1007/ s00405-020-05959-z.

Oded Cohen

oded915@gmail.com

1 Department of Otolaryngology, Head and Neck Surgery, Kaplan Medical Center, Rehovot, Israel

2 Department of Radiology, Kaplan Medical Center, Rehovot, Israel

3 Department of Pathology, Kaplan Medical Center, Rehovot, Israel

4 Hebrew University and Hadassah Medical School, Jerusalem, Israel 